\title{
Microfluidics-generated graphene oxide microspheres and their application to removal of perfluorooctane sulfonate from polluted water
}

\author{
Changwei Zhao ${ }^{1,2}(\varangle)$, Jing Fan², Dong Chen ${ }^{2}, Y_{i} X^{1}$, and Tao Wang ${ }^{3}$ \\ ${ }^{1}$ State Key Laboratory of Environmental Aquatic Chemistry, Research Center for Eco-Environmental Sciences, Chinese Academy of \\ Sciences, Beijing 100085, China \\ ${ }^{2}$ School of Engineering and Applied Sciences, Harvard University, 29 Oxford St., Cambridge, MA 02138, USA \\ ${ }^{3}$ The State Key Laboratory of Chemical Engineering, Department of Chemical Engineering, Tsinghua University, Beijing 100084, China
}

\author{
Received: 20 November 2015 \\ Revised: 30 November 2015 \\ Accepted: 2 December 2015 \\ (C) Tsinghua University Press \\ and Springer-Verlag Berlin \\ Heidelberg 2015

\section{KEYWORDS} \\ microfluidic, \\ graphene oxide, \\ perfluorooctane sulfonate \\ (PFOS), \\ adsorption, \\ water treatment
}

\begin{abstract}
Monodisperse graphene oxide (GO) microspheres were synthesized via microfluidics technology as a novel adsorbent for rapid (in $2 \mathrm{~min}$ ) and high efficiency $(98 \%)$ removal of perfluorooctane sulfonate (PFOS) from water. This novel material is a potential solution for treatment of bioaccumulative organic polluted water. To achieve improved performance, $\mathrm{Mg}^{2+}$ was introduced into GO, and the metal composite exhibited significantly improved PFOS removal efficiency owing to bridging and interaction between $\mathrm{Mg}^{2+}$ and the PFOS molecules, which was supported by density functional theory and X-ray photoelectron spectroscopy (XPS). This facile strategy may be extended to the synthesis of other spheres with unique structural features for application in water treatment.
\end{abstract}

it is essential to develop an effective method for removal of PFOS from surface water to ensure the safety of water resources for human beings. To this end, adsorption technology is a proven and effective method for removal of PFOS from water using carbonaceous materials [19-24]. Among the carbonaceous adsorbent candidates, graphene oxide (GO), as a newly emerging member of the graphite family with a unique structure, exhibits great promise for potential

Address correspondence to zhaocw@rcees.ac.cn 
application in the water treatment field [25-32]. However, to date, there is no reported investigation on the utilization of GO as an adsorbent to remove PFOS from water. It is a timely matter to find an effective adsorption medium to tackle this critical water pollution problem. Porous microspheres are one of the top choices for this purpose due to their high specific surface area, delivering ability, and surface permeability, and consequently higher adsorption rate.

Previously, microfluidic methods have been developed as a novel approach for the controllable synthesis of monodisperse particles. The microfluidic method also has many advantages such as stable yield, controllable structures, and uniform particle size [33-42]. Because of the ability to control the structures of the final emulsion, the microfluidic method has emerged as a promising and versatile technique to generate monodisperse emulsion droplets such as microgels, polymeric particles, compounds, and composite particles [43-49].

Herein, we describe a straightforward microfluidic approach for generating monodisperse hydrogel microspheres with GO microparticles as an effective adsorbent. The GO concentration in the resultant microspheres can be finely tuned and the microspheres have a uniform GO distribution. Magnesium ions are commonly present and detected in water, but there is little information available regarding exploitation of magnesium for PFOS removal by adsorption. Based on the potential and charge neutralization capacity of magnesium ions, these ions may strengthen the cross-linkage between the PFOS contaminants and affect the separation performance. Herein, we investigate the efficiency of these microspheres for PFOS removal from surface water samples with and without $\mathrm{Mg}^{2+}$ ions. The improved PFOS removal efficiency observed in the presence of $\mathrm{Mg}^{2+}$ is interpreted by simulating the geometry and bonding of $\mathrm{Mg}^{2+}$ and PFOS molecules based on density functional theory (DFT) and X-ray photoelectron spectroscopy (XPS) analysis.

\section{Experimental}

\subsection{Preparation of graphene oxide microspheres}

Water-in-oil (W/O) emulsion drops were first generated as templates for preparing the microspheres using a polydimethylsiloxane (PDMS)-based microfluidic device made by standard soft-lithography. The inner phase comprised an aqueous solution containing $20 \mathrm{wt}$ \% poly-(ethylene glycol)diacrylate (PEG-DA, $M_{\mathrm{W}}=750$, Sigma-Aldrich), 0.5 wt.\% 2-hydroxy-2methylpropiophenone as the photoinitiator (SigmaAldrich), and $0.5 \mathrm{wt} . \%$ double layer graphene oxide (US Research Nanomaterials). The outer phase was composed of a fluorinated oil, HFE 7500 (3 M), with $1 \mathrm{wt.} \%$ of Krytox-PEG surfactant to stabilize the emulsion drops against coalescence. The velocity of the two phases in the microfluidic device was controlled by syringe pumps (PHD 2000, Harvard Apparatus, USA). Monodisperse drops were generated by controlling the flow rates of the outer phase and inner phase at 1,000 and $200 \mu \mathrm{L} / \mathrm{h}$, respectively. UV light $(365 \mathrm{~nm})$ was then used to irradiate the emulsion drops for photopolymerization to form microspheres, in which the GO material was embedded in the PEGDA network. Subsequently, the microspheres were washed with isopropyl alcohol and deionized water three times, respectively. At the end, intact microspheres were obtained.

\subsection{Characterization}

Bright-field and fluorescence images were obtained with a Leica inverted fluorescence microscope equipped with a digital camera (Hamamatsu, C4742-95) and Simple PCI acquisition software (Compix). Optical and confocal microscopy images were obtained with a Leica TCS SP5 confocal microscope. The morphology and structure of the microspheres was characterized using a Hitachi S-800 scanning electron microscope (SEM). XPS spectra were acquired with a PHI Quantera SXM Scanning X-ray microprobe. The operating pressure was $4.5 \times 10^{-12}$ Bar with an $\mathrm{Al}-\mathrm{K} \alpha$ X-ray anode radiation source was as the excitation source $(h v=1,486.7 \mathrm{eV})$. XPS peak software was used for curve fitting analysis of the C 1 s spectra. The XPS spectra used Shirley-type background subtraction; the Gaussian-Lorentzian peak shape was used after performing background subtraction. The zeta potential of the membrane surfaces was measured by using a Zetasizer Nano ZS 90 series (Malvern, UK) instrument. 


\subsection{Adsorption experiments}

The adsorption performance of the GO microspheres was examined by calculating the change in the concentration of PFOS (99\%, AccuStandard, Inc., USA). A $25 \mathrm{~mL}$ aqueous solution was prepared with $100 \mathrm{ppb}$ PFOS, $0.005 \mathrm{~g}$ GO microspheres, and $1 \mathrm{mM} \mathrm{MgCl}_{2}$ (99\%, Fisher Scientific) at $\mathrm{pH}=7,25^{\circ} \mathrm{C}$. The solution was vibrated on an orbital shaker at a speed of $130 \mathrm{rpm}$. A fixed volume $(10 \mu \mathrm{L})$ of solution was withdrawn at set time intervals of $20 \mathrm{~s}$, filtered through a $0.22 \mu \mathrm{m}$ membrane filter needle, and injected into the ultraperformance liquid chromatography-tandem mass spectrometer (UPLC-MS/MS) for analysis. The PFOS concentrations were measured via UPLC-MS/MS using an UPLC system (Waters Corp., USA) equipped with a C18 column $(\mathrm{BEH}$, particle size $1.7 \mu \mathrm{m}, 2.1 \times 150 \mathrm{~mm}$ i.d.) and an MS system Quattro Premier XE tandem quadrupole mass spectrometer (Waters Corp., USA) with an electrospray ionization source. The mobile phase contained a binary mixture of (a) $10 \mathrm{mmol} / \mathrm{L}$ ammonium acetate in MilliQ water and (b) acetonitrile applied at a flow rate of $0.2 \mathrm{~mL} / \mathrm{min}$. The ratio of (a) to (b) was 3:7 and the injection volume was $10 \mu \mathrm{L}$. The cone voltage and collision energy were $30 \mathrm{~V}$ and
$11 \mathrm{eV}$ respectively, and the selected ion monitoring (SIM) model was used to quantify the analytes $(\mathrm{m} / \mathrm{z}=$ 499.05 for PFOS).

The PFOS removal efficiency $(R)$ was defined as

$$
R(\%)=\left(1-\frac{C_{\mathrm{p}}}{C_{\mathrm{f}}}\right) \times 100
$$

where $C_{\mathrm{f}}$ and $C_{\mathrm{p}}$ are the PFOS concentrations in the feed and residual, respectively.

\subsection{DFT calculation}

The DFT Becke three-parameter nonlocal exchange functional [47] was used to calculate the geometry of the molecules. The frequencies were used to confirm the optimized structures as ground states without an imaginary frequency.

\section{Results and discussion}

\subsection{Preparation and characterization of droplets}

A cross-junction microfluidic device was used to generate monodisperse drops with the inner phase broken up by the outer phase (Fig. 1(a)). The drops

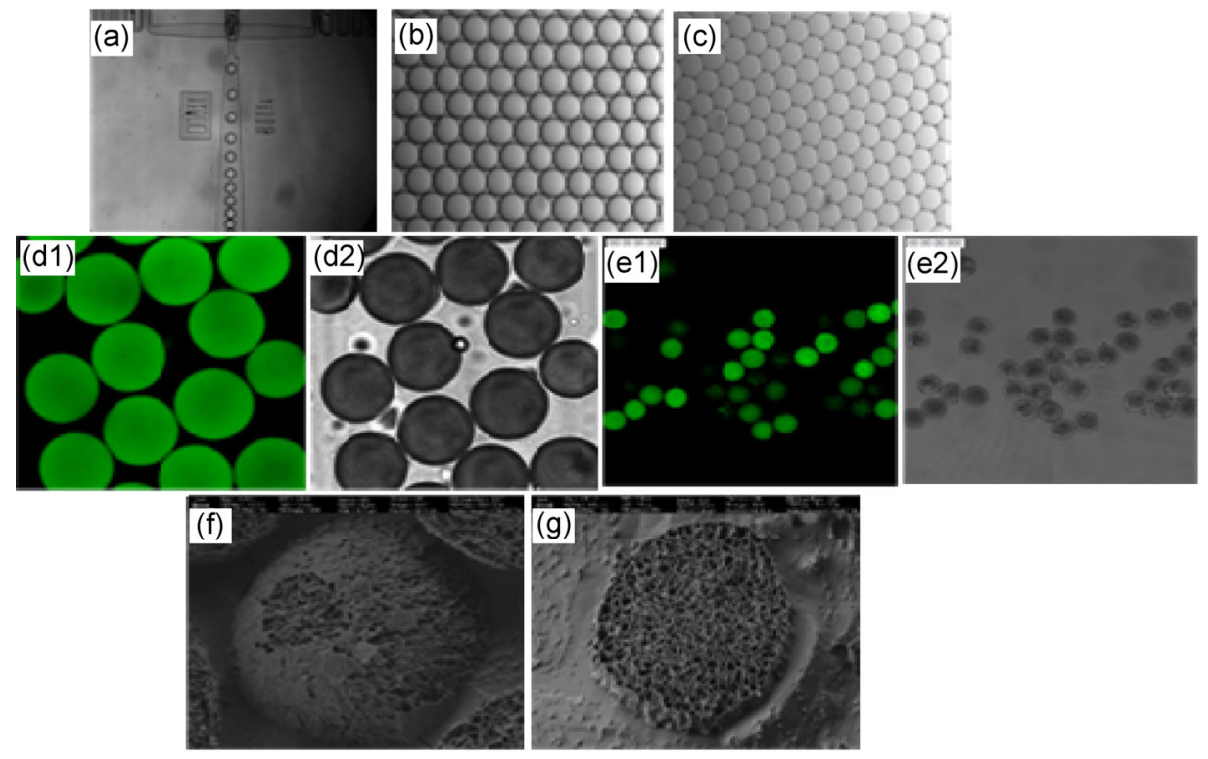

Figure 1 (a) Formation of W/O emulsion drops at the cross-junction. (b) Optical micrograph of the monodisperse drops containing PEG-DA and graphene. (c) Optical micrograph of the deformed drops. (d1) Fluorescence microscope image of the drops. (d2) Brightfield microscope image of the drops at the same area as in (d1). (e1) Fluorescence microscope image of the polymerized microspheres. (e2) Bright-field microscope image of polymerized microspheres at the same area as in (e1). (f) Cryo-SEM images of a microsphere showing the porous surface structure. (g) Cryo-SEM image of the cross-section of a microsphere. 
were collected in a chamber with two parallel glass slides and the drops assembled into a single-layer hexagonal packing structure due to the high monodispersity, as shown in Fig. 1(b). After removing the oil phase from the suspension, the droplets were transferred onto the glass substrate. The drops deformed into an hexagonal shape due to partial evaporation of the volatile HFE oil (Fig. 1(c)).

To characterize the uniformity of the structure, the inner fluid was doped with a fluorescent dye to observe the emulsions under confocal microscopy. Figures $1(\mathrm{~d} 1)$ and $1(\mathrm{~d} 2)$ demonstrate the excellent encapsulation efficiency based on encapsulation of the hydrophilic fluorescent dye, where the fluorescent dye was encapsulated inside the polymersome. After irradiating the drops with UV light $(365 \mathrm{~nm})$ in a chamber for $10 \mathrm{~min}$, monodisperse GO microspheres were obtained, as shown in Figs. 1(e1) and 1(e2). The fluorescence intensity for the drops and microspheres could be quantified as 49.95 and 47.79 , respectively, which further indicated that uniform microspheres were generated. Based on cryo-SEM visualization (Figs. 1(f) and 1(g)), the microspheres were porous, both on the surface and internally, which is advantageous for pollutant removal.

\subsection{Adsorption performance}

To verify the adsorption performance of the GO microspheres, we first prepared two common aqueous solutions containing sulforhodamine $B$ as the model molecules, and added GO microspheres to one of them (Fig. 2(a)). For the sample with the added GO microspheres, after $10 \mathrm{~min}$, the solution changed to almost colorless from its original red color (Fig. 2(b)), again clearly indicating that the developed microspheres can effectively adsorb free molecules in the aqueous environment. We also used sulforhodamine $\mathrm{B}$ to characterize the adsorption performance of the microspheres. The microspheres without fluorescent dye were dispersed in an aqueous solution of sulforhodamine B (Fig. 2(a)).

Over a period of about $2 \mathrm{~min}$, the dye gradually diffused to the inside of the spheres, where the dye accumulated in the spheres due to the presence of GO, as shown in Figs. 2(d) and 2(e). This confirms the
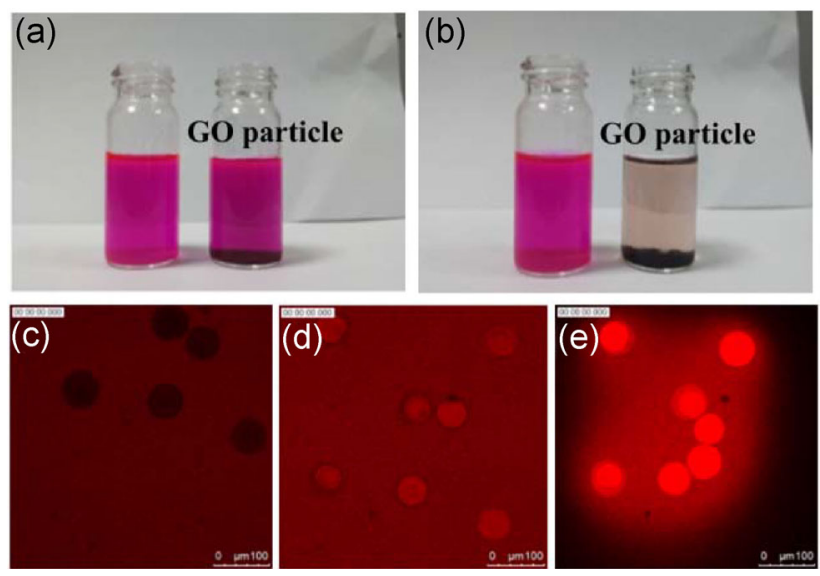

Figure 2 Effective absorption of fluorescent dye molecules in bulk by PEGDA-GO microspheres: (a) 0 and (b) 10 min after adding PEGDA-GO microspheres. Time-lapse confocal microscope images showing the process of dye diffusion into the microspheres at (c) 0 , (d) 1 and (e) 2 min.

great capacity of the GO microspheres to adsorb free molecules in water due to their porous structure.

Furthermore, to demonstrate the application of the GO microspheres to removal of persistent organic pollutants, the GO microspheres, as a novel adsorbent, were applied to PFOS removal. Because common divalent cations are co-existent in real water samples, here, magnesium ions were used as a representative to illustrate the effect of the cation type. Two feed systems, one with $100 \mathrm{ppb}$ PFOS only and the other with a mixture of $100 \mathrm{ppb}$ PFOS and $1 \mathrm{mM} \mathrm{Mg}^{2+}$, were examined. A control experiment was also performed by adding PEG-DA microspheres without encapsulated GO.

Figure 3 shows that the GO microspheres rapidly removed PFOS within $1 \mathrm{~min}$, and equilibrium was reached within approximately 2 min with a removal efficiency of $>95 \%$. To the best of our knowledge, the adsorption speed and capacity of $5,300 \mathrm{mg} \cdot \mathrm{g}^{-1} \mathrm{~s}$ is much higher than previously reported values [3]. This superior performance may be ascribed to the merits of the GO structure for adsorption and the diffusion capacity. However, low PFOS removal efficiency was achieved by using the microspheres without GO. This confirms that GO plays an important role in the PFOS adsorption process. We attribute the marked enhancement of the PFOS removal efficiency in the initial $1 \mathrm{~min}$ to the fact that PFOS was first primarily adsorbed on the GO microspheres. 


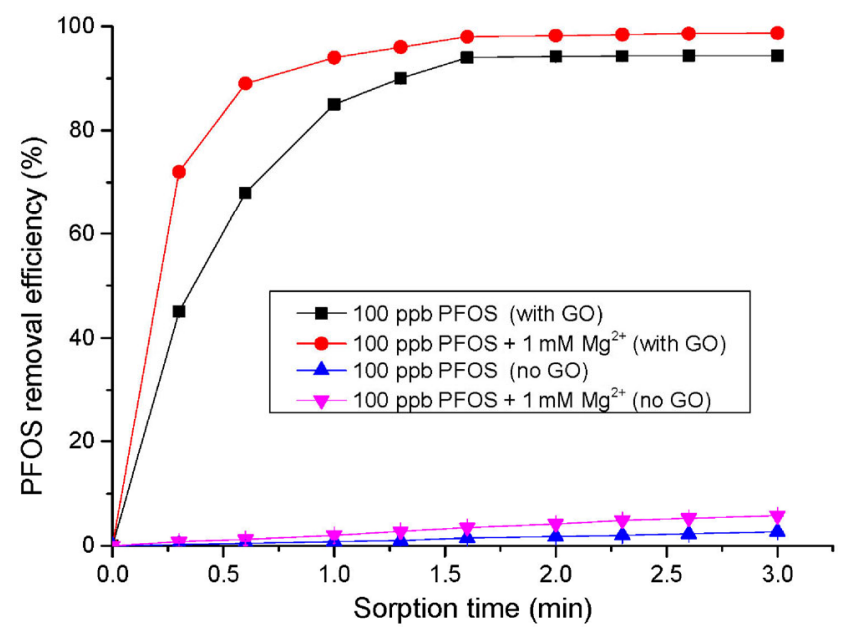

Figure 3 Removal of PFOS by GO microspheres versus spheres without encapsulated GO.

Interestingly, it was also found that the presence of $\mathrm{Mg}^{2+}$ can improve the PFOS removal efficiency (98\%) relative to the microspheres without $\mathrm{Mg}^{2+}$. This might be because the microsphere surface is negatively charged (the zeta potential is $-5 \mathrm{mV}$ ), and therefore the $\mathrm{Mg}^{2+}$ ions improve the surface adsorption capacity. Moreover, $\mathrm{Mg}^{2+}$ can bridge and interact with the PFOS molecules, thereby increasing the adsorption capability.

\subsection{Mechanism analysis}

To further study the mechanism of the interaction between the $\mathrm{Mg}^{2+}$ and PFOS molecules on the microscopic scale, DFT was used to simulate the interaction of $\mathrm{Mg}^{2+}$ with the PFOS molecules. The simulated geometries and structural parameters of the $\mathrm{Mg}^{2+}$ ionbound PFOS molecules are presented in Fig. 4 and Table 1.

Figures 4(a) and 4(b) respectively show the structures of $\mathrm{H}_{2} \mathrm{O}$ and $\mathrm{Mg}\left(\mathrm{H}_{2} \mathrm{O}\right)_{6}{ }^{2+}$ as the stable species in solution. Frontier orbital analysis shows that the highest occupied molecular orbital (HOMO) of anionic PFOS is primarily localized on the sulfonate head group (Fig. $4(\mathrm{c})$ ), and the $-\mathrm{SO}_{3}$ groups are the active sites for binding with the positively charged $\mathrm{Mg}^{2+}$ ion. The $\mathrm{Mg}^{2+}$ ion may interact with one or two PFOS anions to yield two bridging structures as follows

$$
\begin{aligned}
& \mathrm{CF}_{3}\left(\mathrm{CF}_{2}\right)_{7} \mathrm{SO}_{3}^{-}+\mathrm{Mg}\left(\mathrm{H}_{2} \mathrm{O}\right)_{6}^{2+} \rightarrow \\
& \mathrm{Mg}\left[\mathrm{CF}_{3}\left(\mathrm{CF}_{2}\right)_{7} \mathrm{SO}_{3}\right]^{+}\left(\mathrm{H}_{2} \mathrm{O}\right)_{4}+2 \mathrm{H}_{2} \mathrm{O}
\end{aligned}
$$

(a)

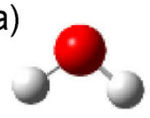

(d)

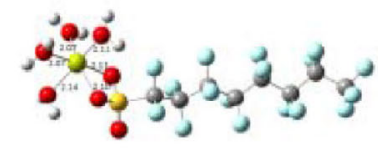

(b)

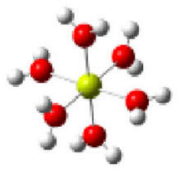

(c)

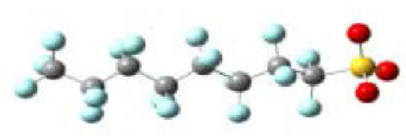

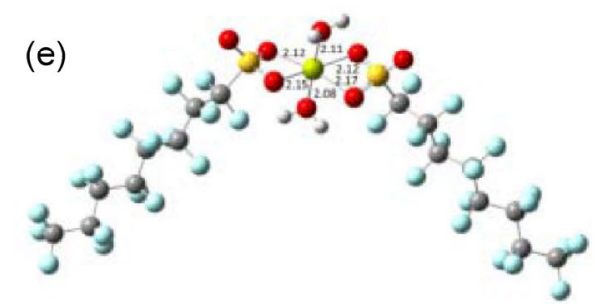

Figure 4 (a) Structure of $\mathrm{H}_{2} \mathrm{O}$, (b) structure of $\mathrm{Mg}\left(\mathrm{H}_{2} \mathrm{O}\right)_{6}^{2+}$, (c) structure and $\mathrm{HOMO}$ of $\mathrm{PFOS}$, (d) geometry of $\mathrm{Mg}^{2+}$ ion bound to one PFOS molecule, (e) geometry of $\mathrm{Mg}^{2+}$ ion bound to two PFOS molecules. Yellow, dark yellow, red, gray, and blue circles denote $\mathrm{S}, \mathrm{Mg}$, $\mathrm{O}, \mathrm{C}$, and $\mathrm{F}$ atoms, respectively. The isosurface plots of the HOMO orbitals were generated with an isodensity value of 0.02 a.u.

Table 1 Molecule-chain length and select parameters calculated based on DFT

\begin{tabular}{ccccc}
\hline Structures & Molecule-chain length $(\AA)$ & $\mu($ Debye $)$ & $H(\mathrm{~kJ} / \mathrm{mol})$ & $S(\mathrm{~kJ} /(\mathrm{mol} \cdot \mathrm{K}))$ \\
\hline $\mathrm{H}_{2} \mathrm{O}$ & - & 2.09 & $-200,602.51$ & 0.188849 \\
$\mathrm{Mg}\left(\mathrm{H}_{2} \mathrm{O}\right)_{6}^{2+}$ & - & 0 & $-1,727,965.08$ & 0.507783 \\
$\mathrm{CF}_{3}\left(\mathrm{CF}_{2}\right)_{7} \mathrm{SO}_{3}^{-}$ & 12.8 & 22.9 & $-6,894,319.99$ & 0.771433 \\
$\mathrm{CF}_{3}\left(\mathrm{CF}_{2}\right)_{7} \mathrm{SO}_{3} \mathrm{Mg}^{+}\left(\mathrm{H}_{2} \mathrm{O}\right)_{4}$ & 16.1 & 31.2 & $-8,221,736.86$ & 1.014294 \\
$\mathrm{CF}_{3}\left(\mathrm{CF}_{2}\right)_{7} \mathrm{SO}_{3} \mathrm{MgO}_{3} \mathrm{~S}-$ & 22.0 & 2.5 & $-14,715,196.57$ & 1.500454 \\
$\left(\mathrm{CF}_{2}\right)_{7} \mathrm{CF}_{3}\left(\mathrm{H}_{2} \mathrm{O}\right)_{2}$ & & & \\
\hline
\end{tabular}

閳 TNIVERSITY PRESS 


$$
\begin{gathered}
2 \mathrm{CF}_{3}\left(\mathrm{CF}_{2}\right)_{7} \mathrm{SO}_{3}^{-}+\mathrm{Mg}\left(\mathrm{H}_{2} \mathrm{O}\right)_{6}^{2+} \\
\rightarrow \mathrm{CF}_{3}\left(\mathrm{CF}_{2}\right)_{7} \mathrm{SO}_{3} \mathrm{MgO}_{3} \mathrm{~S}\left(\mathrm{CF}_{2}\right)_{7} \mathrm{CF}_{3}\left(\mathrm{H}_{2} \mathrm{O}\right)_{2}+4 \mathrm{H}_{2} \mathrm{O}
\end{gathered}
$$

Based on DFT calculation and thermodynamic analysis, the above reactions result in formation of the $\mathrm{CF}_{3}\left(\mathrm{CF}_{2}\right)_{7} \mathrm{SO}_{3} \mathrm{Mg}^{+}\left(\mathrm{H}_{2} \mathrm{O}\right)_{4}$ or $\mathrm{CF}_{3}\left(\mathrm{CF}_{2}\right)_{7} \mathrm{SO}_{3} \mathrm{MgO}_{3} \mathrm{~S}\left(\mathrm{CF}_{2}\right)_{7} \mathrm{CF}_{3}\left(\mathrm{H}_{2} \mathrm{O}\right)_{2}$ configuration depending on the number of PFOS molecules bound to $\mathrm{Mg}^{2+}$ (Figs. 4(d) and 4(e)). Formation of the $\mathrm{CF}_{3}\left(\mathrm{CF}_{2}\right)_{7} \mathrm{SO}_{3} \mathrm{Mg}_{+}\left(\mathrm{H}_{2} \mathrm{O}\right)_{4}$ structure enhanced the polarity of the molecule ( $\mu$ increased from 22.9 to 31.2), which promoted interaction with the negatively charged GO microsphere surface.
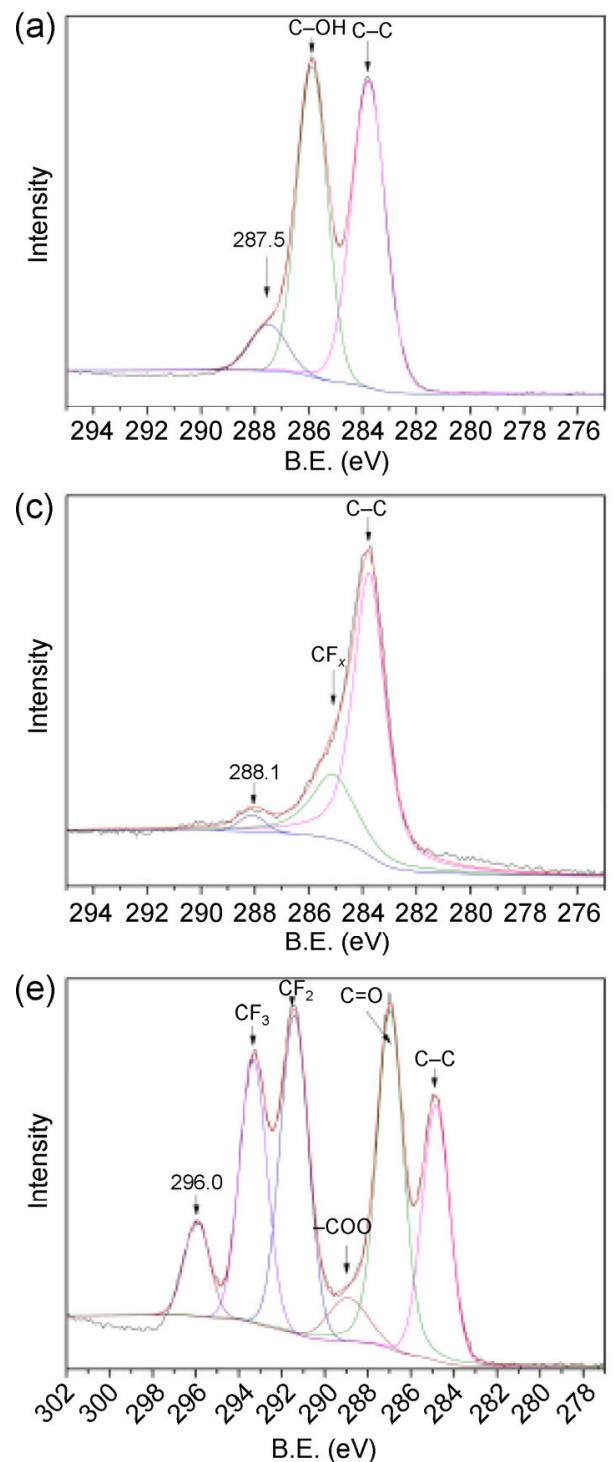

The vibrational properties of the two states before and after PFOS adsorption were also investigated by XPS (Fig. 5) and Table 2.

Figures 5(a) and 5(c) show the C 1s XPS spectra of $\mathrm{GO}$ and the standard PFOS material; the corresponding binding energies are summarized in Table 2. When $\mathrm{Mg}^{2+}$ and PFOS were co-existent (Fig. 5(c)), the spectra of PFOS with $\mathrm{MgCl}_{2}$ showed significant changes; the C-C peak was negatively shifted from 284.4 to $283.8 \mathrm{eV}$ and a new peak $(288.1 \mathrm{eV})$ was observed that has not been reported in previous literature. The disappearance of the $\mathrm{CF}_{2}$ peak and the shift of the $\mathrm{CF}_{3}$ peak to $285.1 \mathrm{eV}$ indicate that the electron cloud density of
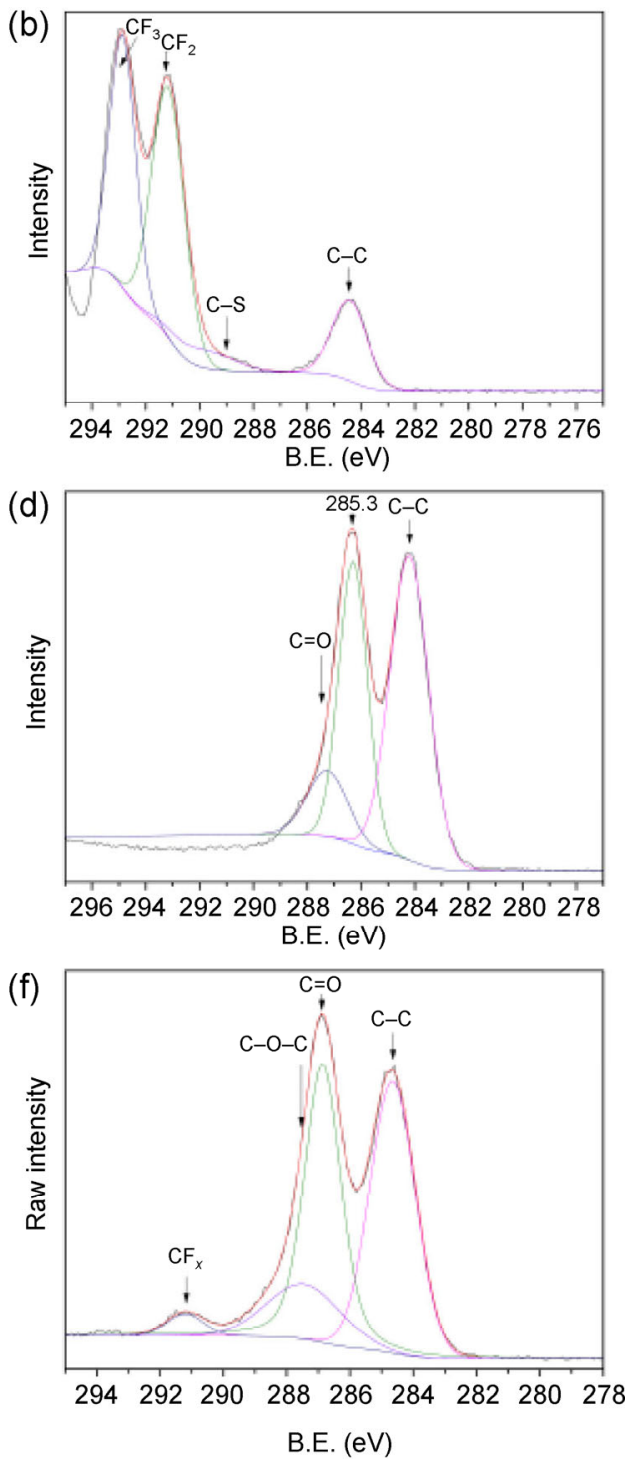

Figure 5 XPS spectra. (a) Graphene oxide, (b) standard PFOS material, (c) PFOS with $\mathrm{MgCl}_{2}$, (d) graphene oxide with $\mathrm{MgCl}_{2}$, (e) graphene oxide with PFOS, (f) graphene oxide with PFOS and $\mathrm{MgCl}_{2}$. 
Table 2 Binding energy data

\begin{tabular}{|c|c|c|}
\hline Substance & $\begin{array}{l}\text { Binding energy } \\
(\mathrm{eV})\end{array}$ & $\begin{array}{c}\text { The types of } \\
\text { bonds }\end{array}$ \\
\hline \multirow[t]{3}{*}{ Graphene oxide [48] } & 283.8 & $\mathrm{C}-\mathrm{C}$ \\
\hline & 285.9 & $\mathrm{C}-\mathrm{OH}$ \\
\hline & 287.5 & $\mathrm{C}=\mathrm{O}$ \\
\hline \multirow[t]{4}{*}{ PFOS [49] } & 284.4 & $\mathrm{C}-\mathrm{C}$ \\
\hline & 298.7 & $\mathrm{C}-\mathrm{S}$ \\
\hline & 291.2 & $\mathrm{CF}_{2}$ \\
\hline & 292.9 & $\mathrm{CF}_{3}$ \\
\hline \multirow[t]{3}{*}{$\mathrm{PFOS}+\mathrm{MgCl}_{2}$} & 283.8 & $\mathrm{C}-\mathrm{C}$ \\
\hline & 285.1 & $\mathrm{CF}_{x}$ \\
\hline & 288.1 & Unknown \\
\hline \multirow{3}{*}{$\begin{array}{c}\text { Graphene oxide }+ \\
\mathrm{MgCl}_{2}\end{array}$} & 284.2 & $\mathrm{C}-\mathrm{C}$ \\
\hline & 286.3 & $\mathrm{C}-\mathrm{OH}$ \\
\hline & 287.2 & $\mathrm{C}=\mathrm{O}$ \\
\hline \multirow{6}{*}{$\begin{array}{l}\text { Graphene oxide }+ \\
\text { PFOS }\end{array}$} & 284.8 & $\mathrm{C}-\mathrm{C}$ \\
\hline & 287.0 & $\mathrm{C}=\mathrm{O}$ \\
\hline & 288.9 & $-\mathrm{COO}^{-}$ \\
\hline & 291.4 & $\mathrm{CF}_{2}$ \\
\hline & 293.3 & $\mathrm{CF}_{3}$ \\
\hline & 296.0 & Unknown \\
\hline \multirow{4}{*}{$\begin{array}{c}\text { Graphene }+ \text { PFOS } \\
+\mathrm{MgCl}_{2}\end{array}$} & 284.6 & $\mathrm{C}-\mathrm{C}$ \\
\hline & 286.9 & $\mathrm{C}=\mathrm{O}$ \\
\hline & 287.5 & $\mathrm{C}-\mathrm{O}-\mathrm{C}$ \\
\hline & 291.2 & $\mathrm{CF}_{x}$ \\
\hline
\end{tabular}

these two functional groups increased. Therefore, these phenomena prove that $\mathrm{Mg}^{2+}$ can chemically bond to the negative $\mathrm{SO}_{3}^{-}$groups of the PFOS molecules. Adding $\mathrm{MgCl}_{2}$ to $\mathrm{GO}$ (as shown in Fig. 5(d)) caused the $\mathrm{C}-\mathrm{C}$ bond energies to shift from 283.8 to $284.3 \mathrm{eV}$. The disappearance of the $\mathrm{C}-\mathrm{OH}$ peak $(285.9 \mathrm{eV})$ in Fig. 5(a) after the adsorption process and the appearance of the peak at $286.3 \mathrm{eV}$ confirm that $\mathrm{Mg}^{2+}$ is chemically bonded to the $\mathrm{GO}$ adsorbent. The $\mathrm{C}=\mathrm{O}$ binding energy at $287.5 \mathrm{eV}$ was negatively shifted to $287.2 \mathrm{eV}$, demonstrating that $\mathrm{Mg}^{2+}$ can increase the electron cloud density of GO. The $\mathrm{Mg}^{2+}$ ions can be adsorbed on the negative sites of the GO surface. Figure 5(e) demonstrates that the addition of PFOS to GO caused significant changes, including the appearance of the C 1s peak (288.9 and $296.0 \mathrm{eV}$ ) after adsorption, confirming that the PFOS molecules are chemically bonded to the GO adsorbent. The disappearance of the $\mathrm{C} 1 \mathrm{~s}$ peak at $285.9 \mathrm{eV}$ and the negative shift of the $\mathrm{C}=\mathrm{O}$ peak to $287.0 \mathrm{eV}$ show that there are some interactions between the carboxyl group and the PFOS molecules. The positive shift of the $\mathrm{CF}_{2}$ and the $\mathrm{CF}_{3}$ peaks from 291.2 to $291.4 \mathrm{eV}$ and 292.9 to $293.3 \mathrm{eV}$, respectively, confirm that GO contained adsorbed PFOS molecules and the electron cloud density decreased. When $\mathrm{Mg}^{2+}$ and PFOS were both added (Fig. 5(f)), the C-C bond energy was positively shifted from 283.8 to $284.6 \mathrm{eV}$ and the $\mathrm{C}=\mathrm{O}$ peak at $287.5 \mathrm{eV}$ was negatively shifted to $286.9 \mathrm{eV}$. The disappearance of the $\mathrm{C}-\mathrm{OH}$ peak at $285.9 \mathrm{eV}$ might indicate transformation of these species to $\mathrm{C}-\mathrm{O}-\mathrm{C}$ groups with a binding energy of $287.5 \mathrm{eV}$, and the new peaks at $291.2 \mathrm{eV}$ are attributed to $\mathrm{CF}_{x}$. Comparison of Figs. 5(d) and 5(e) shows that GO can adsorb both PFOS molecules and $\mathrm{Mg}^{2+}$ ions. Moreover, the adsorbed $\mathrm{Mg}^{2+}$ ions can attract the anionic $\mathrm{SO}_{3}^{-}$ groups to the GO surface, thereby playing a bridging role in neutralizing the negative surface charge. The $-\mathrm{SO}_{3}-\mathrm{Mg}^{+}$groups on the molecules then undergo attractive interactions with the negatively charged GO surface and can be adsorbed on the GO surface. The presence of $\mathrm{Mg}^{2+}$ would increase the capacity for adsorption of PFOS owing to the bridging during the adsorption process (Fig. 6).

Thus, the adsorption of PFOS on the GO microsphere surface is enhanced accordingly with improved PFOS removal efficiency.

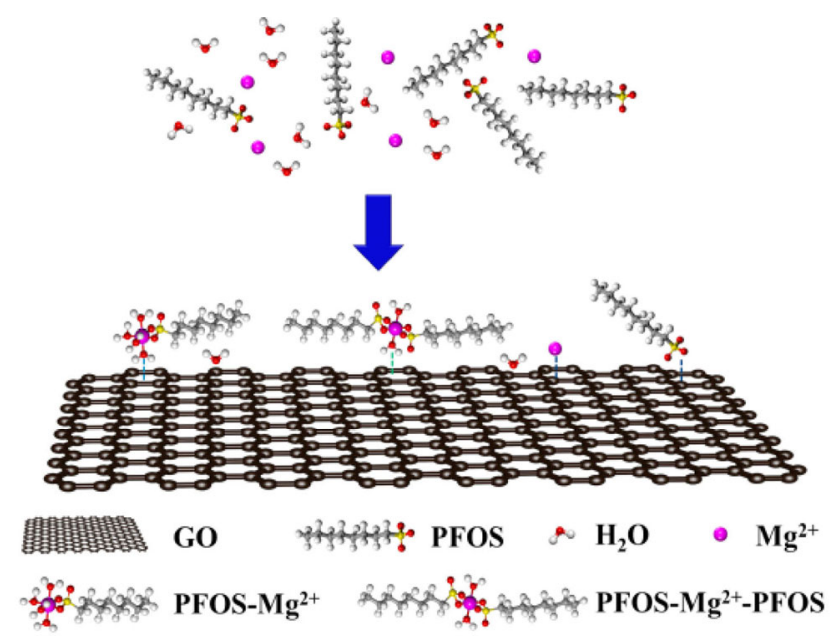

Figure 6 Schematic of the interaction of $\mathrm{Mg}^{2+}$, PFOS, and graphene oxide. 


\section{Conclusions}

Monodisperse hydrogel microspheres with encapsulated GO were developed as a novel adsorbent for water treatment. The microspheres not only efficiently adsorbed the dye molecules in water but also removed PFOS from water, and the efficiency of PFOS removal reached $98 \%$ in the presence of $\mathrm{Mg}^{2+}$ within $2 \mathrm{~min}$. This is attributed to the interactions and bridging of the microspheres with $\mathrm{Mg}^{2+}$ and PFOS molecules, which is supported by XPS analysis and density functional theory calculation. This new strategy should facilitate extensive research on microfluidic technology and GO materials, and pave the way for potential applications of these materials in water treatment in the near future.

\section{Acknowledgements}

We would like to thank Prof. David A. Weitz at Harvard University for his guidance and sincerely help the fabrication part of this work has been done in his lab at Harvard University, and the National Science and Technology Support Program of China (No. 2012BAJ25B02).

\section{References}

[1] Quiñones, O.; Snyder, S. Occurrence of perfluoroalkyl carboxylates and sulfonates in drinking water utilities and related waters from the United States. Environ. Sci. Technol. 2009, 43, 9089-9095.

[2] Beesoon, S.; Martin, J. W. Isomer-specific binding affinity of perfluorooctanesulfonate (PFOS) and perfluorooctanoate (PFOA) to serum proteins. Environ. Sci. Technol. 2015, 49, 5722-5731.

[3] Pual, A. G.; Jones, K. C.; Sweetman, A. J. A first global production, emission, and environmental inventory for perfluorooctane sulfonate. Environ. Sci. Technol. 2009, 43, 386-392.

[4] Deng, S. B.; Zhou, Q.; Yu, G.; Huang, J.; Fan, Q. Removal of perfluorooctanoate from surface water by polyaluminium chloride coagulation. Water Res. 2011, 45, 1774-1780.

[5] Lasier, P. J.; Washington, J. W.; Hassan, S. M.; Jenkins, T. M. Perfluorinated chemicals in surface waters and sediments from northwest Georgia, USA, and their bioaccumulation in Lumbriculus variegatus. Environ. Toxicol. Chem. 2011, 30,
2194-2201.

[6] Lupton, S. J.; Huwe, J. K.; Smith, D. J.; Dearfield, L. L.; Johnston, J. J. Distribution and excretion of perfluorooctane sulfonate (PFOS) in beef cattle (Bos taurus). J. Agric. Food Chem. 2014, 62, 1167-1173.

[7] Hansmeier, N.; Chao, T. C.; Herbstman, J. B.; Goldman, L. R.; Witter, F. R.; Halden, R. U. Elucidating the molecular basis of adverse health effects from exposure to anthropogenic polyfluorinated compounds using toxicoproteomic approaches. J. Proteome Res. 2015, 14, 51-58.

[8] Cressey, D. Manufacturing chemicals may damage the immune system. Nature News [Online], Jan 24, 2012. http://www.nature.com/news/manufacturing-chemicals-maydamage-the-immune-system-1.9877 (accessed Nov 20, 2015).

[9] Eschauzier, C.; Beerendonk, E.; Scholte-Veenendaal, P.; de Voogt, P. Impact of treatment processes on the removal of perfluoroalkyl acids from the drinking water production chain. Environ. Sci. Technol. 2012, 46, 1708-1715.

[10] Wang, T.; Wang, Y. W.; Liao, C. Y.; Cai, Y. Q.; Jiang, G. B. Perspectives on the inclusion of perfluorooctane sulfonate into the stockholm convention on persistent organic pollutants. Environ. Sci. Technol. 2009, 43, 5171-5175.

[11] Yan, T. T.; Chen, H.; Jiang, F.; Wang, X. Adsorption of perfluorooctane sulfonate and perfluorooctanoic acid on magnetic mesoporous carbon nitride. J. Chem. Eng. Data 2014, 59, 508-515.

[12] Gao, Y.; Fu, J. J.; Cao, H. M.; Wang, Y. W.; Zhang, A. Q.; Liang, Y.; Wang, T.; Zhao, C. Y.; Jiang, G. B. Differential accumulation and elimination behavior of perfluoroalkyl acid isomers in occupational workers in a manufactory in China. Environ. Sci. Technol. 2015, 49, 6953-6962.

[13] Fu, Z. Q.; Wang, Y.; Wang, Z. Y.; Xie, H. B.; Chen, J. W. Transformation pathways of isomeric perfluorooctanesulfonate precursors catalyzed by the active species of P450 enzymes: In silico investigation. Chem. Res. Toxicol. 2015, 28, 482-489.

[14] Wang, T.; Zhao, C. W.; Li, P.; Li, Y.; Wang, J. Fabrication of novel poly(m-phenylene isophthalamide) hollow fiber nanofiltration membrane for effective removal of trace amount perfluorooctane sulfonate from water. J. Membr. Sci. 2015, 477, 74-85.

[15] Arvaniti, O. S.; Hwang, Y.; Andersen, H. R.; Stasinakis, A. S.; Thomaidis, N. S.; Aloupi, M. Reductive degradation of perfluorinated compounds in water using Mg-aminoclay coated nanoscale zero valent iron. Chem. Eng. J. 2015, 262, 133-139.

[16] Lin, H.; Wang, Y. J.; Niu, J. F.; Yue, Z. H.; Huang, Q. G. Efficient sorption and removal of perfluoroalkyl acids (PFAAs) from aqueous solution by metal hydroxides generated in 
situ by electrocoagulation. Environ. Sci. Technol. 2015, 49, 10562-10569.

[17] Lyu, X. J.; Li, W. W.; Lam, P. K. S.; Yu, H. Q. Insights into perfluorooctane sulfonate photodegradation in a catalystfree aqueous solution. Sci. Rep. 2015, 5, 9353.

[18] Kleinstreuer, N. C.; Yang, J.; Berg, E. L.; Knudsen, T. B.; Richard, A. M.; Martin, M. T.; Reif, D. M.; Judson, R. S.; Polokoff, M.; Dix, D. J. et al. Phenotypic screening of the toxcast chemical library to classify toxic and therapeutic mechanisms. Nat. Biotechnol. 2014, 32, 583-591.

[19] Zhang, Q. Y.; Deng, S. B.; Yu, G.; Huang, J. Removal of perfluorooctane sulfonate from aqueous solution by crosslinked chitosan beads: Sorption kinetics and uptake mechamism. Bio. Technol. 2011, 102, 2265-2271.

[20] Higgins, C. P.; Luthy, R. G. Sorption of perfluorinated surfactants on sediments. Environ. Sci. Technol. 2006, 40, 7251-7256.

[21] Li, X. N.; Chen, S.; Quan, X.; Zhang, Y. B. Enhanced adsorption of PFOA and PFOS on multiwalled carbon nanotubes under electrochemical assistance. Environ. Sci. Technol. 2011, 45, 8498-8505.

[22] Liu, A. D.; Goktekin, E.; Gleason, K. K. Cross-linking and ultrathin grafted gradation of fluorinated polymers synthesized via initiated chemical vapor deposition to prevent surface reconstruction. Langmuir 2014, 30, 14189-14194.

[23] Yu, Q.; Zhang, R. Q.; Deng, S. B.; Huang, J.; Yu, G. Sorption of perfluorooctane sulfonate and perfluorooctanoate on activated carbons and resin: Kinetic and isotherm study. Water Res. 2009, 43, 1150-1158.

[24] Xia, X. H.; Chen, X.; Zhao, X. L.; Chen, H. T.; Shen, M. H. Effects of carbon nanotubes, chars, and ash on bioaccumulation of perfluorochemicals by Chironomus plumosus larvae in sediment. Environ. Sci. Technol. 2012, 46, 12467-12475.

[25] Xu, J.; Wang, L.; Zhu, Y. F. Decontamination of bisphenol A from aqueous solution by graphene adsorption. Langmuir 2012, 28, 8418-8425.

[26] Pal, S. K. Versatile photoluminescence from graphene and its derivatives. Carbon 2015, 88, 86-112.

[27] Wang, X. B.; Huang, S. S.; Zhu, L. H.; Tian, X. L.; Li, S. H.; Tang, H. Q. Correlation between the adsorption ability and reduction degree of graphene oxide and tuning of adsorption of phenolic compounds. Carbon 2014, 69, 101-112.

[28] Li, Y. H.; Du, Q. J.; Liu, T. H.; Sun, J. K.; Jiao, Y. Q.; Xia, Y. Z.; Xia, L. H.; Wang, Z. H.; Zhang, W.; Wang, K. L. et al. Equilibrium, kinetic and thermodynamic studies on the adsorption of phenol onto graphene. Mater. Res. Bull. 2012, 47, 1898-1904.

[29] Liu, T. H.; Li, Y. H.; Du, Q. J.; Sun, J. K.; Jiao, Y. Q.; Yang,
G. M.; Wang, Z. H.; Xia, Y. Z.; Zhang, W.; Wang, K. L. et al. Adsorption of methylene blue from aqueous solution by graphene. Colloids Surf. B Biointerfaces 2012, 90, 197-203.

[30] Carreño, N. L. V.; Escote, M. T.; Valentini, A.; McCafferty, L.; Stolojan, V.; Beliatis, M.; Mills, C. A.; Rhodes, R.; Smith, C. T. G.; Silva, S. R. P. Adsorbent 2D and 3D carbon matrices with protected magnetic iron nanoparticles. Nanoscale 2015, 7, 17441-17449.

[31] Kim, J.; Cote, L. J.; Kim, F.; Yuan, W.; Shull, K. R.; Huang, J. X. Graphene oxide sheets at interfaces. J. Am. Chem. Soc. 2010, 132, 8180-8186.

[32] Madadrang, C. J.; Kim, H. Y.; Gao, G. H.; Wang, N.; Zhu, J.; Feng, H.; Gorring, M.; Kasner, M. L.; Hou, S. F. Adsorption behavior of EDTA-graphene oxide for $\mathrm{Pb}$ (II) removal. ACS Appl. Mater. Interfaces 2012, 4, 1186-1193.

[33] Wang, W.; Zhang, M. J.; Chu, L. Y. Microfluidic approach for encapsulation via double emulsions. Curr. Opin. Pharmacol. 2014, 18, 35-41.

[34] Abate, A. R.; Kutsovsky, M.; Seiffert, S.; Windbergs, M.; Pinto, L. F. V.; Rotem, A.; Utada, A. S.; Weitz, D. A. Synthesis of monodisperse microparticles from non-newtonian polymer solutions with microfluidic devices. Adv. Mater. 2011, 23, 1757-1760.

[35] Kim, S. H.; Weitz, D. A. One-step emulsification of multiple concentric shells with capillary microfluidic devices. Angew. Chem. 2011, 123, 8890-8893.

[36] Chen, L. D.; Lai, C.-Z.; Granda, L. P.; Fierke, M. A.; Mandal, D.; Stein, A.; Gladysz, J. A.; Bühlmann, P. Fluorous membrane ion-selective electrodes for perfluorinated surfactants: Trace-level detection and in situ monitoring of adsorption. Anal. Chem. 2013, 85, 7471-7477.

[37] Abolhasani, M.; Günther, A.; Kumacheva, E. Microfluidic studies of carbon dioxide. Angew. Chem., Int. Ed. 2014, 53, 7992-8002.

[38] Abou-Hassan, A.; Sandre, O.; Cabuil, V. Microfluidics in inorganic chemistry. Angew. Chem., Int. Ed. 2010, 49, 6268-6286.

[39] Lewis, G. G.; DiTucci, M. J.; Phillips, S. T. Quantifying analytes in paper-based microfluidic devices without using external electronic readers. Angew. Chem., Int. Ed. 2012, 51, 12707-12710

[40] Safavieh, M.; Qasaimeh, M. A.; Vakil, A.; Juncker, D.; Gervais, T. Erratum: Two-aperture microfluidic probes as flow dipoles: Theory and applications. Sci. Rep. 2015, 5, 14885 .

[41] Ng, A. H. C.; Chamberlain, M. D.; Situ, H.; Lee, V.; Wheeler, A. R. Digital microfluidic immunocytochemistry in single cells. Nat. Commun. 2015, 6, 7513. 
[42] Yan, J.; Hu, M.; Li, D.; He, Y.; Zhao, R.; Jiang, X. Y.; Song, S. P.; Wang, L. H.; Fan, C. H. A nano- and micro-integrated protein chip based on quantum dot probes and a microfluidic network. Nano Res. 2008, 1, 490-496.

[43] Li, S. W.; Xu, J. H.; Wang, Y. J.; Luo, G. S. Controllable preparation of nanoparticles by drops and plugs flow in a microchannel device. Langmuir 2008, 24, 4194-4199.

[44] Zhao, Y. J.; Gu, H. C.; Xie, Z. Y.; Shum, H. C.; Wang, B. P.; Gu, Z. Z. Bioinspired multifunctional Janus particles for droplet manipulation. J. Am. Chem. Soc. 2013, 135, 54-57.

[45] Jeong, W. C.; Lim, J. M.; Choi, J. H.; Kim, J. H.; Lee, Y. J.; Kim, S. H.; Lee, G.; Kim, J. D.; Yi, G. R.; Yang, S. M. Controlled generation of submicron emulsion droplets via highly stable tip-streaming mode in microfluidic devices. Lab Chip 2012, 12, 1446-1453.
[46] Persson, H.; Beech, J. P.; Samuelson, L.; Oredsson, S.; Prinz, C. N.; Tegenfeldt, J. O. Vertical oxide nanotubes connected by subsurface microchannels. Nano Res. 2012, 5, 190-198.

[47] Becke, A. D. Density-functional thermochemistry. III. The role of exact exchange. J. Chem. Phys. 1993, 98, 56485652.

[48] Spyrou, K.; Calvaresi, M.; Diamanti, E. K.; Tsoufis, T., Gournis, D.; Rudolf, P.; Zerbetto, F. Graphite oxide and aromatic amines: Size matters. Adv. Funct. Mater. 2015, 25 , 263-269.

[49] Hamilton, C. E.; Lomeda, J. R.; Sun, Z. Z.; Tour, J. M.; Barron, A. R. Radical addition of perfluorinated alkyl iodides to multi-layered graphene and single-walled carbon nanotubes. Nano Res. 2010, 3, 138-145. 